\title{
CLIMA URBANO DE TEFÉ-AM: ANÁLISE EPISÓDICA DA TEMPERATURA DO AR NO CENTRO E NA VILA BOA SORTE DO PERÍODO DE 2014-2015
}

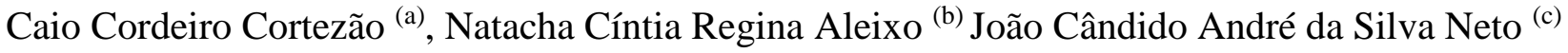 \\ (a) Universidade do Estado do Amazonas, caio_cortezao12@hotmail.com \\ (b) Universidade Federal do Amazonas, natachaaleixo@yahoo.com.br \\ (c) Universidade Federal do Amazonas, joaokandido@yahoo.com.br
}

\section{Eixo: CLIMATOLOGIA EM DIFERENTES NÍVEIS ESCALARES: MUDANÇAS E VARIABILIDADES}

\begin{abstract}
Resumo
Este trabalho teve como objetivo realizar uma análise das diferenças térmicas em duas áreas: Centro e Vila Boa Sorte da cidade de Tefé-AM . Foram coletados os dados de temperatura do ar no período diurno e noturno, nos meses de outubro de 2014, maio e novembro de 2015 e junho e julho de 2016 nos horários de 08:00h e 11:00h e das 18:00h às 21:00h, além, levar em consideração toda a característica do uso do solo das áreas. Os resultados demonstraram que na area Central que possui maior densidade construtiva, fluxo instenso de veículos e pessoas ocorre a concentração elevada de calor e alta amplitude de temperatura em relação ao bairro Vila Boa Sorte. Conclui-se que é preciso a busca de alternativas para a intervenção no ambiente, visando melhorar o planejamento e a produção do espaço da cidade.
\end{abstract}

Palavras-chave: clima urbano, temperatura do ar, Tefé, Amazonas

\section{Introdução}

A expansão territorial urbana ocorre de maneira desordenada e desigual, associada à transformação no balanço de energia nas cidades, gerndo um clima urbano que apresenta impactos negativos diferenciados nos diversos grupos sociais em diferentes contextos territoriais.

Com as alterações do uso do solo, com a retirada da cobertura vegetal, a intensa impermeabilização do solo e a utilização de materiais construtivos como fibrocimento e alumínio que têm sido usados nas construções residenciais, observa-se em diversas pesquisas o aumento da temperatura nos centros urbanos.

O processo de urbanização das cidades, sem planejamento adequado propiciaram o surgimento e agravamento de problemas ambientais, como as ilhas de calor.

A formação de ilhas de calor é o resultado direto das modificações antrópicas na criação do espaço urbano, que interferem no balanço de energia radiativa, provocando alterações na temperatura, umidade do ar e comportamento dos ventos, incidindo diretamente no conforto térmico dos habitantes. (AMORIM, 2000. p.198) 
Conforme SantAnna Neto (2011), tempos dominados por sistemas atmosféricos estáveis são propícios à formação de ilhas de calor, ou a concentração de poluentes na atmosfera, e são alguns dos exemplos de configurações climáticas que afetam a qualidade de vida dos diversos grupos sociais de maneira diferenciada.

De acordo com Carlos (2009), o uso do solo relaciona-se ao processo de produção e ocupação de determinada área na cidade. "O modo de ocupação de determinado lugar da cidade se dá a partir da necessidade de realização de determinada ação, seja de produzir, consumir, habitar ou viver". (CARLOS, 2009. p.45)

As condições específicas da superfície e suas rugosidades, o processo de ocupação e apropriação do espaço urbano e a transformação da paisagem urbana, sendo somados às condições socioeconômica da população, tem evidenciado claramente que com apropriação indevida pelos agentes sociais têm ocorrido impactos negativos no espaço urbano.

Verifica-se que com o processo de evolução da urbanização e dos equipamentos utilizados para atender as necessidades das cidades, promove-se a redução drástica das áreas verdes, o que acaba causando um aumento na temperatura e o aumento da energia radiativa na superfície terrestre, que implica diretamente na absorção térmica. Além disso, o crescimento das áreas impermeabilizadas, a densidade das construções e a pavimentação das vias, são alguns dos fatores que influenciam nos índices de temperatura do ar.

A partir disso, o objetivo do trabalho é analisar as diferenças térmicas em duas áreas da cidade de TeféAM, a Vila Boa Sorte e o Centro.

O município de Tefé-AM localizado na Região do Médio Solimões no estado do Amazonas (figura 1), apresenta população de 61. 453 habitantes (IBGE, 2010) e ainda apresenta escassez de estudos na climatologia, assim esse estudo é fundamental para o conhecimento do clima local, visando também a análise da produção do espaço urbano que ao longo dos anos, vem (re) produzindo seu espaço em função das novas perspectivas da urbanização brasileira, sem considerar os indicadores físico-naturais. (ALEIXO, 2016)

Embora esse processo aconteça gradativamente, é percebível que as cidades, estão mais próximas uma das outras em consequência da articulação e da função que cada uma desempenha, sejam a nível local, regional e global.

O clima e a arborização não foram importantes no processo de produção e no planejamento das cidades, e os impactos causados por esse crescimento desordenado é percebido pela população em seu modo de vida, com intenso uso de ar condicionado no ambiente interno. Além da cidade localizar-se em área de clima 


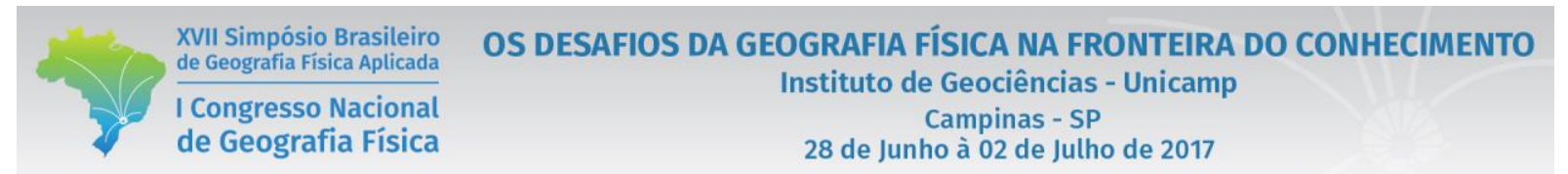

equatorial que naturalmente apresenta condições de alta temperatura e umidade, propiciando desconforto térmico, o clima urbano pode acentuar ainda mais essa problemática acarretando problemas a saúde e bem-estar humano.

As áreas analisadas podem ser observadas na figura 1.

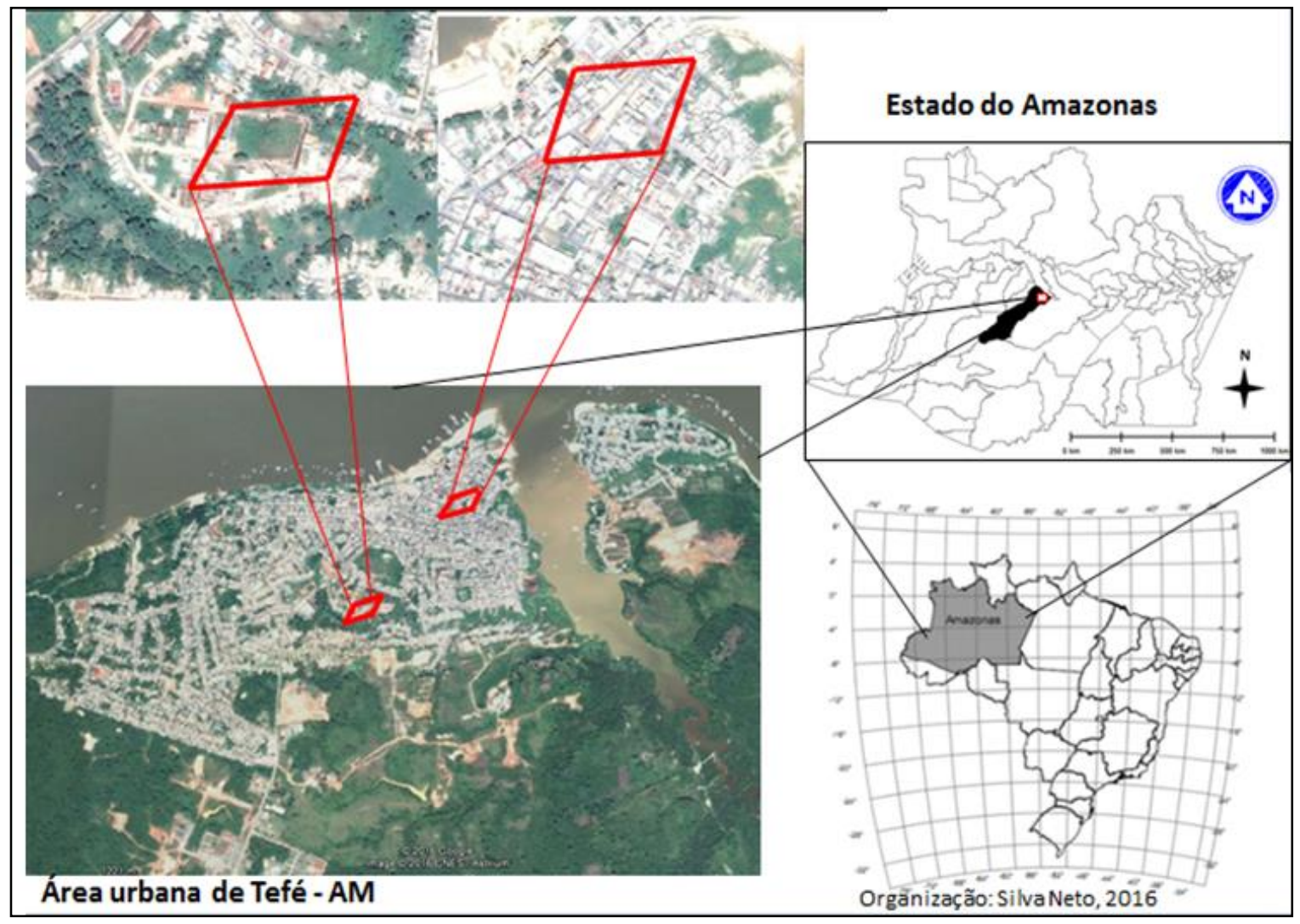

Figura 1. Localização do recorte especial do estudo. (Fonte: Google Earth; IBGE).

\section{Procedimentos metodológicos}

A elaboração do trabalho consistiu na revisão bibliográfica sobre a integração dos elementos do clima com a produção do espaço urbano.

A partir disso, utilizou-se o método de análise proposto por Monteiro (1976) que sugere uma abordagem sistêmica do clima urbano, mediante os canais de percepção humana, com enfoque no subsistema termodinâmico .

No desenvolvimento da presente proposta foram utilizados termohigrômetros (marca Incoterm) necessários para a coleta de dados na cidade de Tefé 


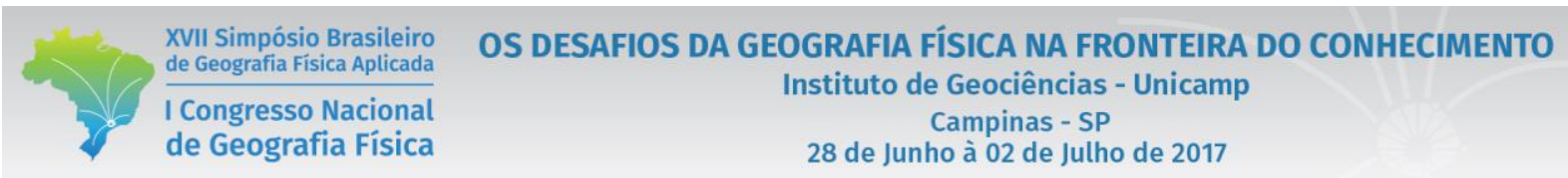

Foram escolhidos os meses para coleta dos dados de temperatura do ar conforme a sazonalidade climática predominante na região. O período chuvoso compreende os meses de dezembro-junho e o período de seca compreende os meses de julho-novembro. Os dados foram coletados no período de uma semana nos meses escolhidos para coleta.

No ano de 2014 no mês de outubro no horário das 08:00h as 11:00h e das 18:00h as 21:00h foi realizada a primeira coleta de dados de temperatura no Centro e na Vila Boa Sorte. No ano de 2015 no mês de maio e novembro foi realizada a segunda e terceira coleta de dados respectivamente no Centro e Vila Boa Sorte.

No Centro encontram-se muitas edificações, avenidas pavimentadas, calçadas, alta densidade de construção e verticalização.

A Vila Boa Sorte apresenta áreas de solos expostos, poucas ruas pavimentadas e vegetação densa arbórea nas ruas, conforme figura 2 .

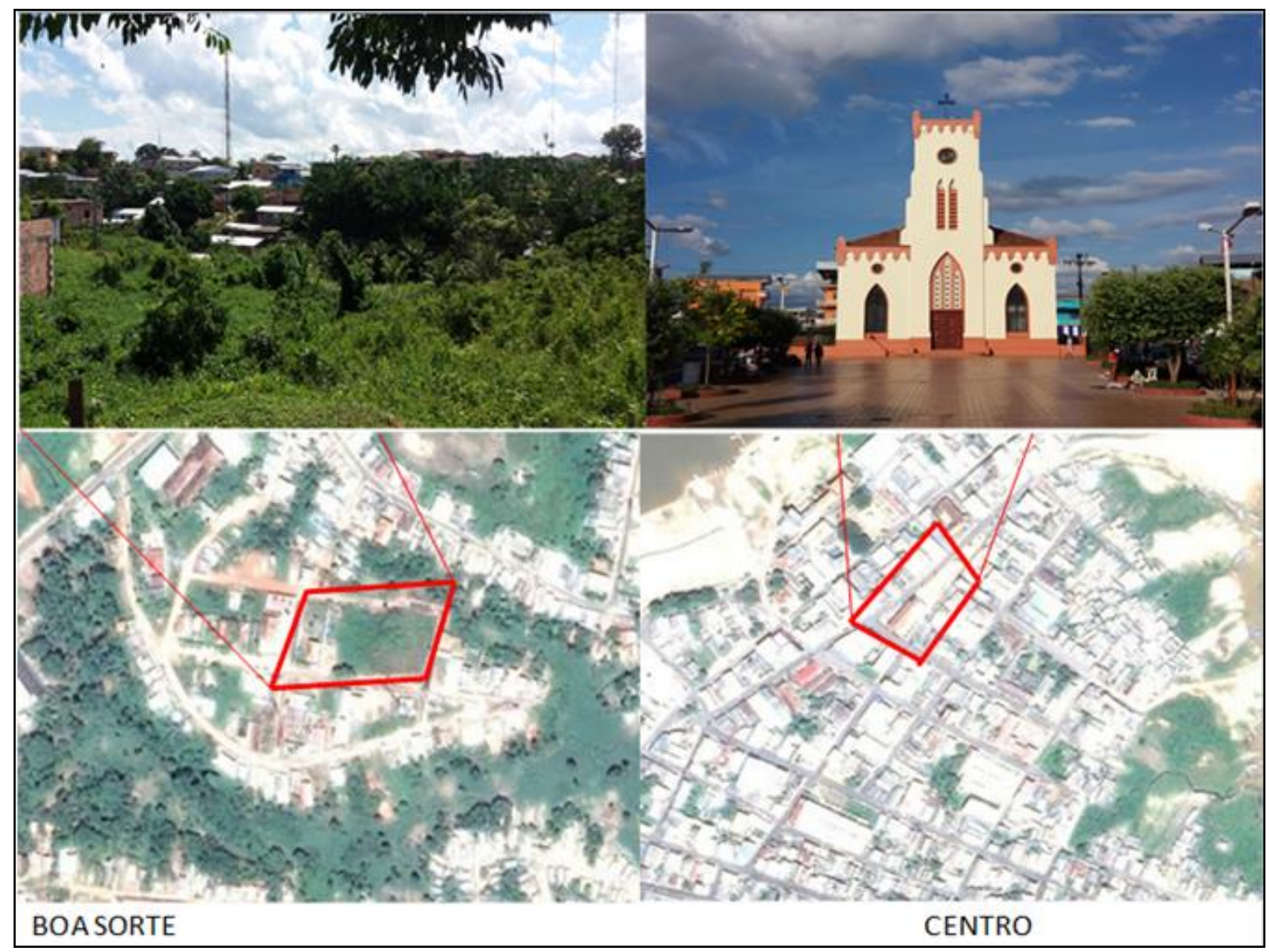

Figura 2. Áreas analisadas na cidade de Tefé-AM. (Fonte: Google Earth; Levantamento de campo).

\section{A Temperatura do ar no Centro e na Vila Boa Sorte}


No ano de 2014, no mês de outubro observou-se que o Centro da cidade teve a temperatura mais elevada durante o dia. Essa área por conter a maior densidade de construção, pavimentação e maior verticalidade potencializa o aumento de temperatura na relação do balanco de energia superfície-atmosfera.

O Centro apresentou maior valor de temperatura com $32,8{ }^{\circ} \mathrm{C}$ entre os dias coletados no período do diurno, enquanto o menor valor de temperatura do ar foi de $26,3{ }^{\circ} \mathrm{C}$ na Vila Boa Sorte, que contém uma vegetação densa, áreas arborizadas e menor densidade construtiva. No período noturno o Centro novamente apresentou a maior temperatura com $31,3^{\circ} \mathrm{C}$ e a menor foi na Vila Boa Sorte com $23,8^{\circ} \mathrm{C}$.

No dia $8 / 10$, por exemplo, o bairro que apresentou a maior temperatura foi o Centro com $26,8^{\circ} \mathrm{C}$ e a menor foi na Vila Boa Sorte com a temperatura de $26,3^{\circ} \mathrm{C}$ no horário das 08:00h. Esse padrão se repetiu no horário das 11:00h., o Centro apresentou maior temperatura entre os pontos analisados com valor de $30,8^{\circ} \mathrm{C}$, e a Vila Boa Sorte a menor temperatura $29,9^{\circ} \mathrm{C}$.

Conforme o gráfico 1, durante a noite, o bairro que apresentou a maior temperatura foi o Centro com $29,4^{\circ} \mathrm{C}$ e a menor foi na Vila Boa Sorte com a temperatura de $27,9^{\circ} \mathrm{C}$ no horário das 18:00hs. Esse padrão se repetiu no horário das 21:00hs, o Centro apresentou maior temperatura entre os pontos analisados com valor de $28,2^{\circ} \mathrm{C}$, e a Vila Boa Sorte com a menor temperatura de $26,3^{\circ} \mathrm{C}$.

Gráfico 1. Temperatura do ar no dia 08/10/2014.

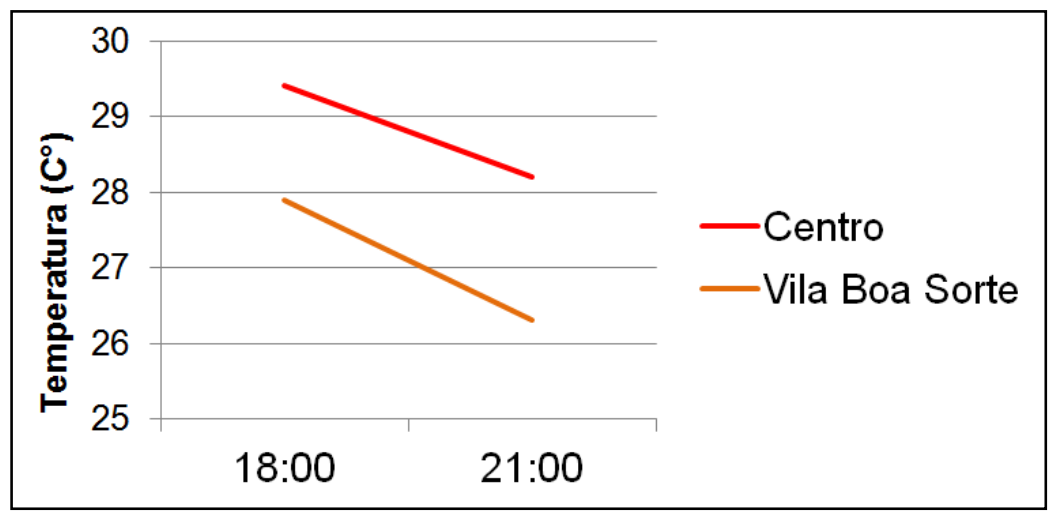

No ano de 2015 a maior temperatura ocorreu no Centro por conter a maior densidade de construção, com valor de $31,3^{\circ} \mathrm{C}$ entre os dias coletados, enquanto o menor valor de temperatura ocorreu com $26,6^{\circ} \mathrm{C}$ na Vila Boa Sorte.

O trabalho de coleta dos dados foi realizado no período da cheia em maio de 2015 , as temperaturas medidas nos locais variaram entre três e seis graus, já em Novembro do mesmo ano de 2015, a maior temperatura ocorreu no Centro com $32,4^{\circ} \mathrm{C}$ entre os dias coletados, enquanto a menor foi $25,1^{\circ} \mathrm{C}$ na Vila Boa Sorte 


\section{OS DESAFIOS DA GEOGRAFIA FÍSICA NA FRONTEIRA DO CONHECIMENTO \\ Instituto de Geociências - Unicamp \\ Campinas - SP \\ 28 de Junho à 02 de Julho de 2017}

No dia 20/05 o bairro que apresentou a maior temperatura foi o Centro com $28,1^{\circ} \mathrm{C}$ e a menor foi no Boa

Sorte com $27,2^{\circ} \mathrm{C}$ no horário das $08: 00 \mathrm{~h}$. Esse padrão se repetiu no horário das 11:00h., o Centro apresentou maior temperatura entre os pontos analisados com valor de $31,2^{\circ} \mathrm{C}$ e o Boa Sorte com a menor temperatura $30,0^{\circ} \mathrm{C}$.

Conforme o Gráfico 2 do dia 20/05 o bairro que apresentou a maior temperatura foi o Centro com $32,0^{\circ} \mathrm{C}$ e a menor foi o Boa Sorte com a temperatura de $31,3^{\circ} \mathrm{C}$ no horário das $18: 00 \mathrm{~h}$. Esse padrão se repetiu no horário das 21:00h., Centro apresentou maior temperatura entre os pontos analisados com valor de $29,3^{\circ} \mathrm{C}$, o Boa Sorte com a menor temperatura de $28,3^{\circ} \mathrm{C}$.

Gráfico 2. Temperatura do ar no dia 20/05/2015.

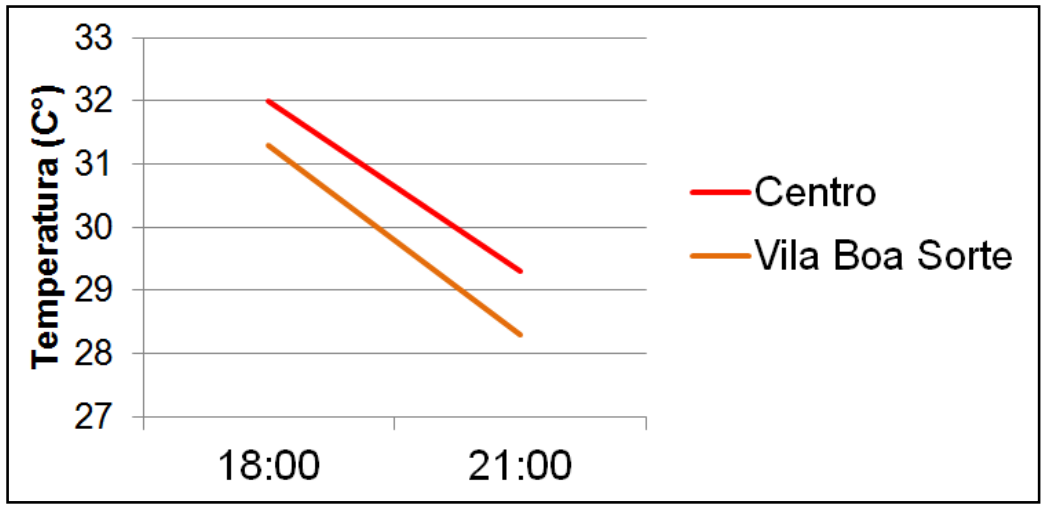

No dia 04/11/2015, época de predomínio da vazante (periodo menos chuvoso) o Bairro que apresentou a maior temperatura foi o Centro que teve a temperatura de $27,8^{\circ} \mathrm{C}$ e a menor foi na Vila Boa Sorte com $27,2^{\circ} \mathrm{C}$, no horário das $08: 00 \mathrm{~h}$. No horário das as $11: 00 \mathrm{~h}$ esse padrão se repetiu o Centro teve a maior temperatura com $32,4^{\circ} \mathrm{C}$ e o Boa Sorte teve a menor temperatura com $31,1^{\circ} \mathrm{C}$.

Conforme o Gráfico 3 do dia 04/11 o bairro que apresentou a maior temperatura foi o Centro com $30,6^{\circ} \mathrm{C}$ e a menor foi na Vila Boa Sorte com a temperatura de $28,8^{\circ} \mathrm{C}$, no horário das $18: 00 \mathrm{~h}$. Esse padrão se repetiu no horário das 21:00h., o Centro apresentou maior temperatura entre os pontos analisados com valor de $27,1^{\circ} \mathrm{C}$ e a Vila Boa Sorte teve a menor temperatura com $25,9^{\circ} \mathrm{C}$. 
Gráfico 3. Temperatura do ar no dia 04/11/2015.

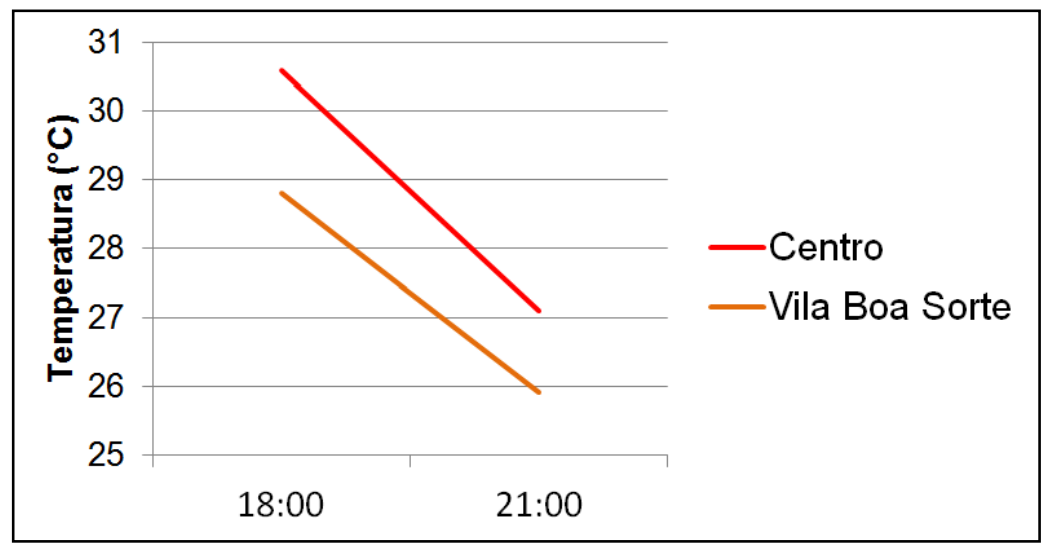

Durante os períodos analisados as maiores diferenças de temperatura entre as áreas ocorreram no periodo noturno no horário das 21:00h, que é quando a energia radiativa está se dissipando na atmosfera e causando o resfriamento da superfície terrestre. Esse horário é considerado o mais adequado para análise térmica do clima local,em especial, das ilhas de calor urbanas.

Nota-se que no ano de 2014 no dia 6/10 a maior amplitude ocorreu as 21 h. com 2,7 de amplitude, já nos dias 8 e 9/10 novamente a maior amplitude ocorreu as 21:00h com 1,9 de amplitude, dia 10 ocorreu as 18:00h com 0,9 de amplitude. (Gráfico 4)

Gráfico 4. Amplitude térmica no mês de outubro de 2014.

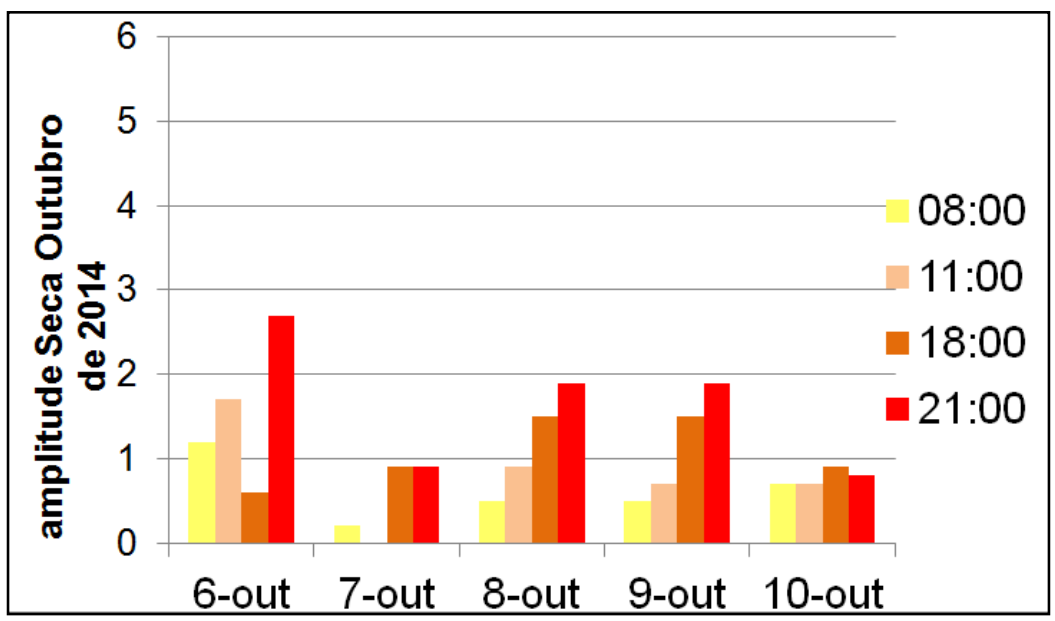

Em maio de 2015 no dia 18 a maior amplitude térmica ocorreu as $21: 00 \mathrm{~h}$ com $4,3^{\circ} \mathrm{C}$ de amplitude térmica, e no dia 19 ocorreu as 18:00h com $4,7^{\circ} \mathrm{C}$ de amplitude. No dia 21 novamente ocorreu as 21:00h com $2,0^{\circ} \mathrm{C}$ de amplitude. (Gráfico 5) 


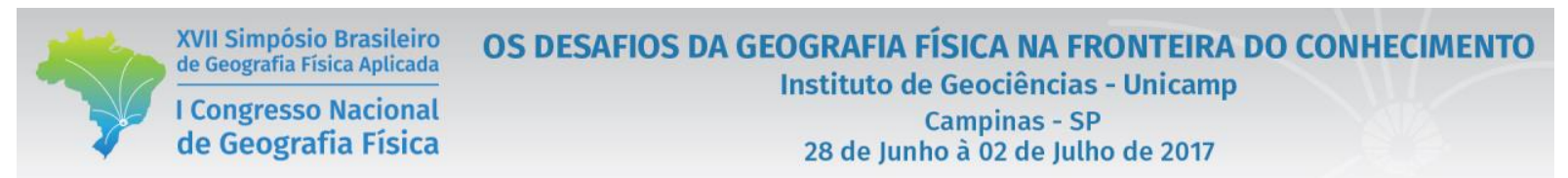

Em novembro de 2015 as maiores amplitudes que ocorreram nos dias 5 e 6 de novembro as 21:00h com $1,9^{\circ} \mathrm{C}$ e $2,3^{\circ} \mathrm{C}$ de amplitude térmica. (Gráfico 6).

Gráfico 5. Amplitude térmica no mês de maio de 2015.

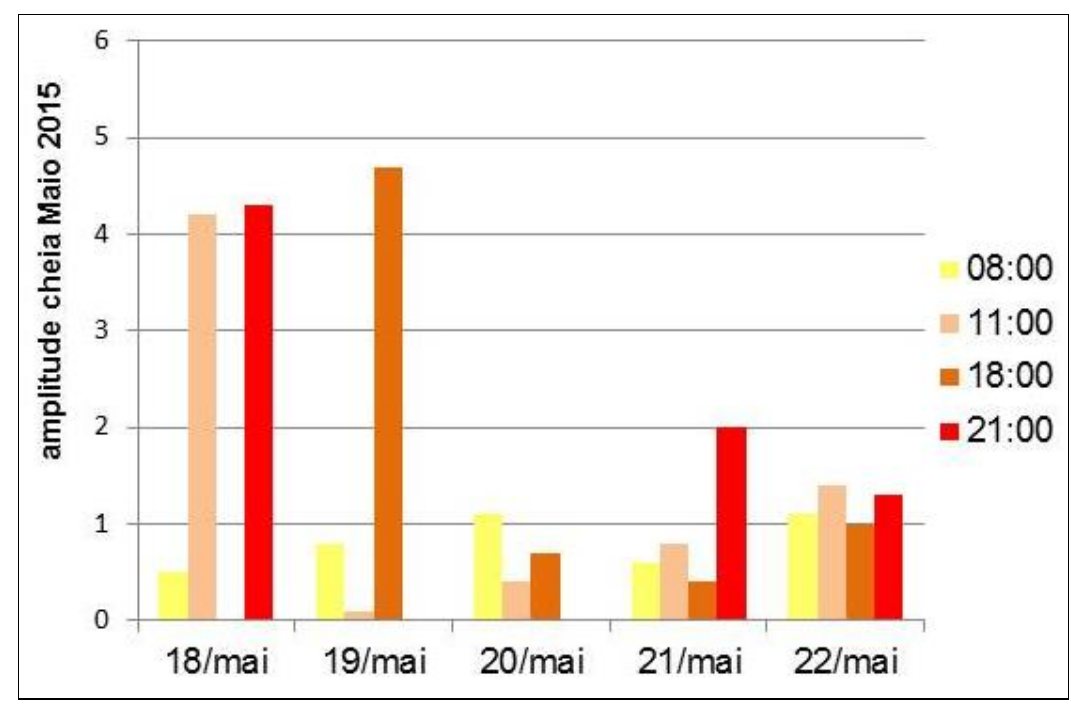

Gráfico 6. Amplitude térmica no mês de novembro de 2015.

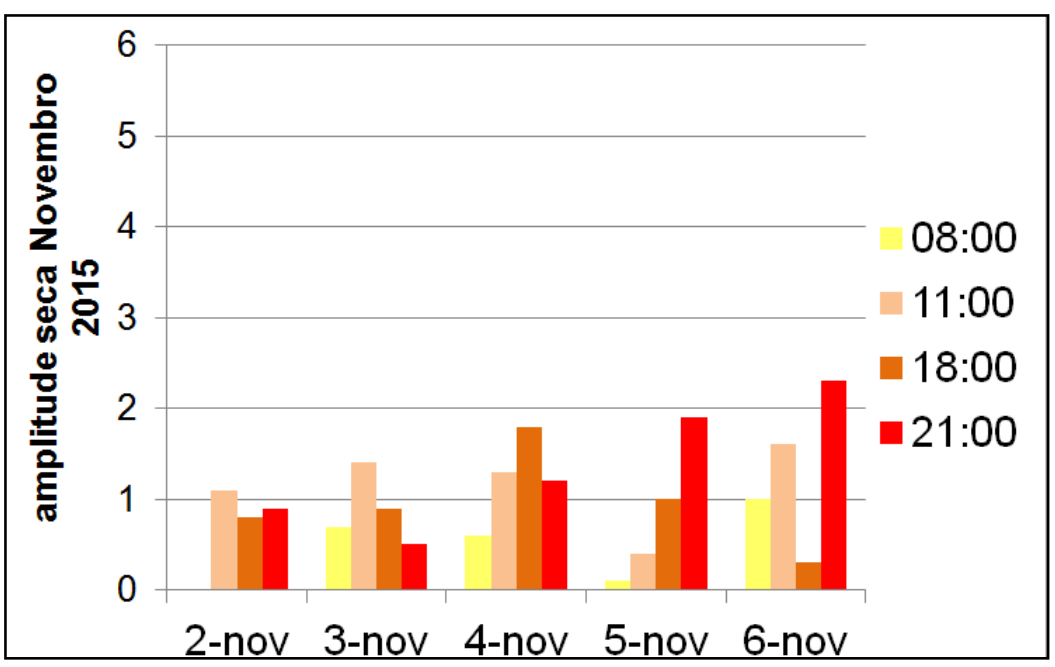

No centro da cidade, conforme os dados analisados ocorreram temperaturas mais elevadas em todos os períodos analisados, enquanto na Vila Boa Sorte as temperaturas foram bem amenas durante o dia, e também durante a noite segundo o estudo realizado.

Os fatores que controlam os diferentes processos na geração do clima urbano são, por um lado, as características do clima regional, no qual a área a ser estudada se insere que impõe o ritmo e a distribuição temporal dos principais elementos climáticos, e por outro, 
os fatores relacionados propriamente ao ambiente urbano, que se modificam em escala local; as transformações produzidas pelo homem na atmosfera urbana afetam o balanço de energia e o balanço hídrico. (LIMA, 2011).

O estudo realizado constatou que na área da Vila Boa Sorte que possui vegetação arbórea densa e menor densidade construtiva as temperaturas são mais amenas, porém, no Centro da cidade com a alta densidade de construção o calor é maior, com temperaturas elevadas devido à construção de casas, prédios e poucas unidades de vegetação arbórea, que prejudica o conforto térmico dos citadinos e pode influenciar na qualidade de vida.

Contudo, é necessário o aprofundamento dos resultados obtidos inicialmente na presente pesquisa, pois, é preciso uma análise integrada do ritmo climático e de outras variáveis relacionadas aos fatores geográficos do clima para compreensão da totalidade do clima urbano e dos estados atmosféricos que estão associados às diferentes magnitudes das ilhas de calor e frescor.

\section{Conclusão}

O processo de produção do espaço urbano da cidade de Tefé tem gerado transformações no meio natural, e vem contribuindo para a geração de um microclima local. Dessa maneira, é preciso intervir na apropriação dos espaços, ter uma política voltada para os recursos do meio ambiente, arborização da cidade e consideração da análise climática no planejamento urbano.

Apesar disso, sabe-se que outros estudos devem ser realizados na cidade para que possamos verificar as áreas de ilhas de calor e frescor, levando em conta a análise de dados de outros bairros, maior temporalidade das medidas e o ritmo climático.

\section{Bibliografia}

ALEIXO, N.C.R.; SILVA NETO, J.C. A. Precipitação e riscos em Tefé-AM. Revista Brasileira de Geografia Física v.08, n.04, 1176-1190, 2015.

AMORIM, M. C. C. T. O clima urbano de Presidente Prudente/SP. Tese de doutoramento. São Paulo: Faculdade de Filosofia, Letras e Ciências Humanas, Universidade de São Paulo/Brasil, 2000.

CARLOS, A. F. A. O Espaço Urbano: Novos Escritos sobre a Cidade. São Paulo: Labur Edições, 2009.

LIMA, G. Características do clima urbano de nova andradina-MS. Dissertação de mestrado em Geografia. UNESP Presidente Prudente, 2011.

MONTEIRO, C.A. de F. Teoria e Clima Urbano. São Paulo: Universidade de São Paulo, Instituto de Geografia, 1976.

SANT'ANNA NETO, J. L. O clima urbano como construção social. Revista Brasileira de Climatologia, vol.8, p. 45-60, 2011. 